\title{
ANALYTICAL REPRESENTATION OF ARCHITECTURAL BUILT HERITAGE. A SKETCH-TO-BIM APPROACH
}

\author{
R. Argiolas ${ }^{1 *}$, V. Bagnolo ${ }^{1}$, S. Cera ${ }^{1}$, G. Sanna ${ }^{1}$ \\ ${ }^{1}$ DICAAR, University of Cagliari, Cagliari, Italy - (raffaele.argiolas, vbagnolo)@unica.it, cera.simone@gmail.com, \\ giancarlo.sanna8@gmail.com
}

KEY WORDS: HBIM, Cultural Heritage, Algorithmic Modelling, Geometrical Analysis, Complex of Santa Croce.

\begin{abstract}
:
HBIM methodology is increasingly used for the management of all aspects of architectural heritage, from survey and analysis to conservation, management and restoration issues.

Application of HBIM are the so-called Scan-to-BIM processes in which the artifact is surveyed with digital techniques of laser scanning and photogrammetry. These techniques result in point clouds, the basis of the subsequent process of informative and geometric modelling of the artifact. The resulting "smart models" are composed of parametric objects rich in information that can be easily updated at any time.

The proposed methodology aims at integrating a study of architectural orders, whose results become preparatory to the subsequent phases of survey and modeling, to the classic Scan-to-BIM workflows. In particular, in the modeling these results have allowed a more targeted choice of techniques used.

The method has been applied to the atrium of the former Jesuit College of Santa Croce in Cagliari, which today hosts one of the seats of the Faculty of Engineering and Architecture of the University of Cagliari; in particular, the atrium of the east body of the former Jesuit College, designed by the Piedmontese architect Antonio Felice De Vincenti, has been modelled.
\end{abstract}

\section{INTRODUCTION}

Although BIM was initially conceived for the construction of 'as-designed' models, the needs of survey and representation of heritage have led to an 'as-built' approach, called Heritage Building Information Modelling (H-BIM), based on a process of reconstruction of the architectural artefact through reverse engineering, which starts from the analysis of the existing and its survey (Murphy et al., 2009).

The HBIM methodology is nowadays widely used for the management of all aspects of the architectural heritage, from surveying and analysis to issues of preservation, management and restoration. This interest is mainly due to the potential that the HBIM methodology offers in terms of collection, storage, processing, management and sharing of information through a multidimensional and multidisciplinary approach.

The practical expression of HBIM finds its fulfilment in the socalled Scan-to-BIM processes in which the artefact is surveyed using laser scanning techniques and photogrammetry, both terrestrial and aerial through the use of drones. The results of the survey are point clouds, from which the process of information and geometric modelling of the artefact starts. The resulting "smart models" are composed of parametric objects rich in information that can be easily updated at any time.

The built heritage is in fact the result of several different historical layers that testify to the transformation of its complex morphology over time. The models must therefore be updated frequently due to new interventions on the built heritage or to changes due to unintentional events in the building fabric such as ageing and decay processes or the effects of catastrophic events (Pocobelli et al., 2018).

There are many potential uses of BIM models of the built heritage. Through the use of sensors, the digital model can be enriched in real time with information on the decay and structural health of the building, also allowing for simulations and predictions.
The proposed methodology is based on the classic Scan-to-BIM workflows, with particular attention to the preliminary survey and modelling phases (Fig. 1). Regarding the preliminary operations, these are often limited to a classification of objects and their semantic hierarchization, with reference to standardised systems (Badenko et al., 2019). In our case, however, it was decided to integrate into the workflow a series of geometric-proportional analyses, in plan and in elevation, and of the architectural objects present; the latter are analysed using as a reference the studies obtainable from historical treatises.

The case study chosen is the entrance hall of the former Jesuit College of Santa Croce in Cagliari, which today houses one of the headquarters of the Faculty of Engineering and Architecture of the University of Cagliari (Fig. 2). The complex is located in the historic district of Castello, founded by Pisa in the 13th century (Scano, 1934), and is the work of the Jesuit architects Giandomenico da Verdina and Giovanni Maria Bernardoni; the work is the first example of Renaissance aesthetics in Sardinia, as well as the first Jesuit architecture on the island (Maltese et al., 2012).

The architectural complex of the former Jesuit college is divided into two main bodies, one of which stands behind the church of Santa Croce, and both develop around a central courtyard, joined by an overpass on what is now via Corte d'Appello. The first body to be completed was the one to the west in 1661, while the one to the east was subsequently extended between 1725 and 1773 by Antonio Felice De Vincenti, an architect from Piedmont (Garofalo, 2012).

De Vincenti was responsible for the construction of the atrium in question, consisting of two levels and marked by fluted and banded columns, on which rest the ten cross vaults arranged in two naves. The type of columns described above can also be found in other works by De Vincenti, such as Palazzo Carignano or Palazzo del Valentino in Turin. 


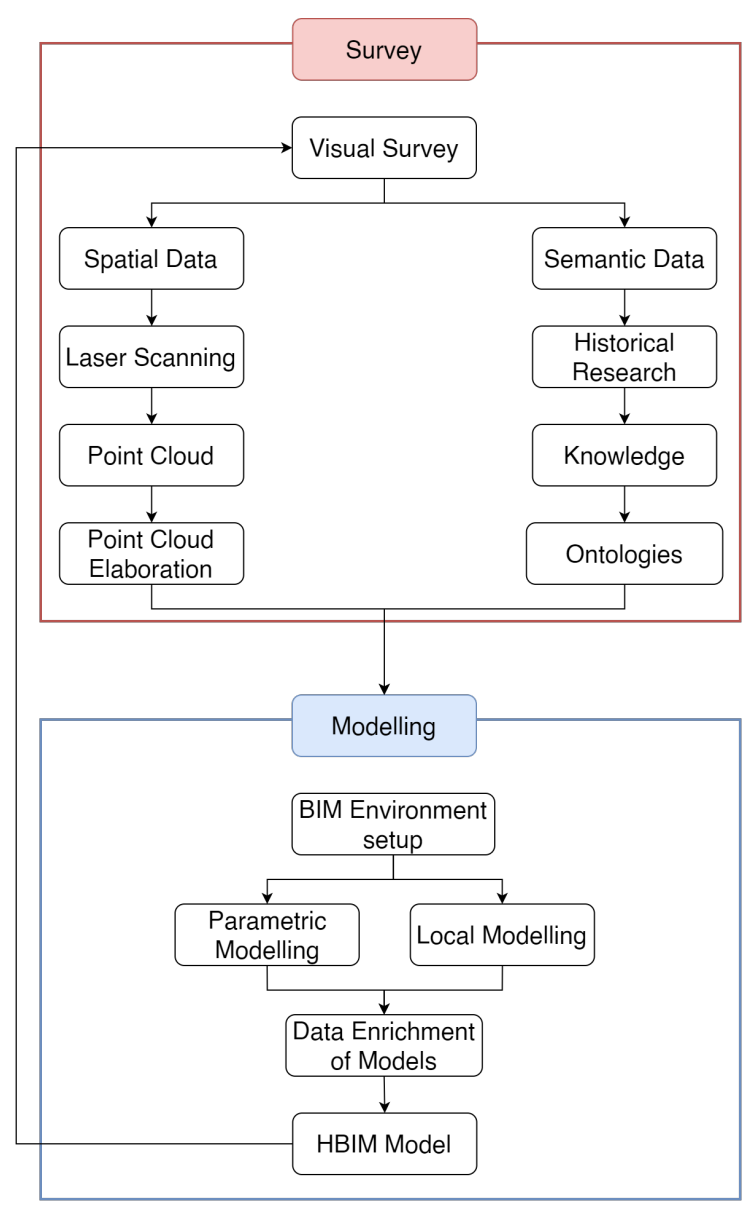

Figure 1. Summary scheme of the proposed workflow.

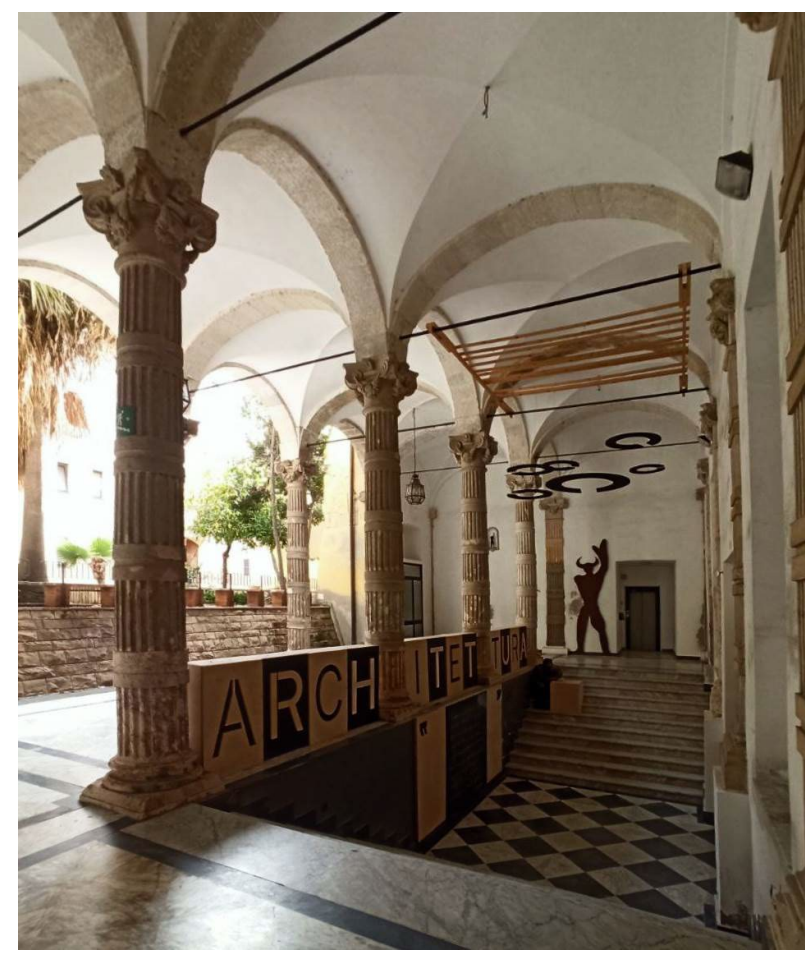

Figure 2. The entrance hall of the former Jesuit College of Santa Croce in Cagliari, today seat of the School of Architecture of the University of Cagliari.

\section{ARCHITECTURAL ORDERS AS A FORMAL SYSTEM IN THE SURVEY OF HISTORICAL BUILDINGS}

"Therefore, since nature has designed the human body so that its members are duly proportioned to the frame as a whole, it appears that the ancients had good reason for their rule, that in perfect buildings the different members must be in exact symmetrical relations to the whole general scheme" (Morgan, 1960).

The recording of a measurement within a survey process must start from the understanding of the compositional laws underlying an architectural space. Architectural orders define a very effective formal system for architectural survey of historic buildings, tracing the reading of the monument to its "structure" both individual elements and relations between the parts and the whole.

Although it is not always possible to think of the existence of a "hidden structure" of the monument, certainly through patient research we can analyse the "conceptual structure" that measures and shapes the architectural space and its parts. This research of the ordering module translates into identifying the algorithm that governs each architectural element and establishes the pivot around which the operational and methodological choices of the survey are set.

Geometry, proportions and module, originally a tool for compositional and constructive systems, today become the "measure" in the architectural survey.

it is necessary and appropriate that the study of a monument must always be approached through drawing. Drawing precedes, accompanies and concludes Laser scanning and image survey-based systems available for surveying historic buildings. Drawing reinvigorates its role as the only true means of expression and understanding of architecture.

As with architectural orders, drawing reveals its central role also in the reading of principles linked to visual perception, also a privileged tool for the design of architecture between the 17th and 18 th centuries.

Despite the apparent simplicity of the codes linked to the architectural orders, the whole complexity of these principles emerges in the processes of knowledge of architecture. The concept of measurement itself is closely linked to the knowledge process but Architectural survey is not only measurement but is above all a reading and interpretation tool. Each element of the final representation is the result of the interpretation of the information, very different from the simple cast of the reality of the point clouds, each point can have multiple returns. As with real objects, we must read and interpret the point cloud data, locate and detect the different parts, segment the point cloud and finally return it as a pointcloud based objects collection.

The compositional and constructive control implemented on the architectural space becomes a reading key in the survey process. Quoting Gregotti, it is no coincidence that "measure" and "modus" have the same root, and that the concept of modus refers to the idea of measure (Gregotti, 1985). Both in the design and survey processes we take possession of the built space and its relationship with the human being as a unit of measurement.

Surveying a monument that can apparently adopt the principles derived from the encodings of architectural orders, the critical analysis of the architecture usually starts with the identification of an alleged module. The module, from its original function as a design tool, thus becomes for us a key to understanding the parts and their relationship with the whole.

The expected architectural system is a collection of hierarchically structured objects identified according to the 
vocabulary of architectural orders. The module identified in the atrium of the former Jesuit College of Santa Croce in Cagliari, is equal to the half-diameter measured at the base of the shaft of the column as Vitruvius taught us.

The hidden structure imposed by the codifications defined in the architectural treaties establishes some reference models which, starting from the Renaissance, take up the canons formalized by Vitruvius in his De Architectura, giving it a value linked not so much to what Vitruvius sets and hands down from ancient culture, but above all to what Vitruvius generated in modern culture (De Fusco, 1968).

In the architectural drawings that have come down to us from the early Renaissance, the study of ancient monuments arises as a means not only for the knowledge and analysis of the architecture of ancient Rome. The purpose of these drawings was rather for a learning of the principles of classical architecture that going beyond the detached studio of Vitruvius made it possible to develop an individual learning path both in drawing and architectural project (Alberti, 1485).

As in the architectural drawing of the Renaissance, even today the setting up of the survey of a monument can take advantage of a preliminary reading conducted through detailed and general sketches, up to the development of the entire structure of the building. Today this same approach takes advantage of recording the coordinates of millions of points on architectural surfaces. The traditional process of reality analysis is accompanied by a similar discretization and segmentation process that starts from the analysis of the point clouds. The architecture of the atrium (which is not made up of points) is divided into a collection of objects governed by geometric principles, similarly in many ways to what happened in the Renaissance.

Admitting many exceptions depending on the treaty, and also in consideration of the variability of geographical contexts, the modulation of architectural orders is not matched by a single geometric construction methodology (Le Duc, 1875) However, there are some mandatory relationships that can constitute invariants and that can contribute to the formation of an idea of architectural survey not as an absolute value, but as a continuous search for some "structures" that mediate the relationship between formal, constructive and material aspects. In an approach aimed at applying the principles of the orders illustrated by accurate graphic constructions, Vignola (1763) theorized the procedure of the submultiples of the module, identifying, as Vitruvius had already done, in the half-diameter of the column the basic module used for the proportioning of the architectural partitions. Just as the architects of the Renaissance, starting with Vitruvius, sought a reorganization of architectural codes, even in the Baroque the same objective continues to be pursued (Kaufman, 1968).

The analyses carried out in our case study, bring the whole and the parts back to the same measure. Thus, both the space of the atrium (Fig. 3) and the proportions of the column (Fig. 4) can be traced back to the same module of the half-diameter measured at the lower end of the shaft of the column.

In particular, regarding the space, the rhythm that arranges the columns in a longitudinal direction is dictated by the module defined according to the treatises by the size of the halfdiameter measured at the lower end of the shaft of the column.

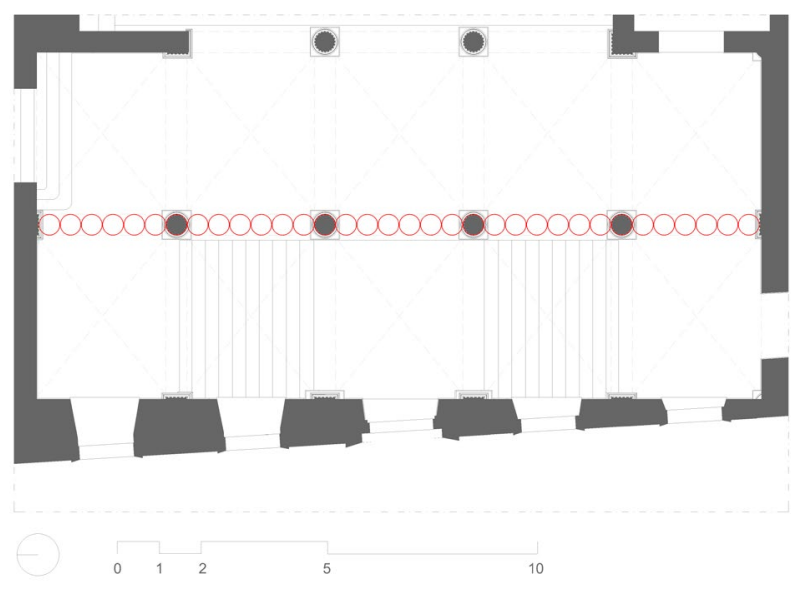

Figure 3. Dimensional analysis of the atrium floor plan.

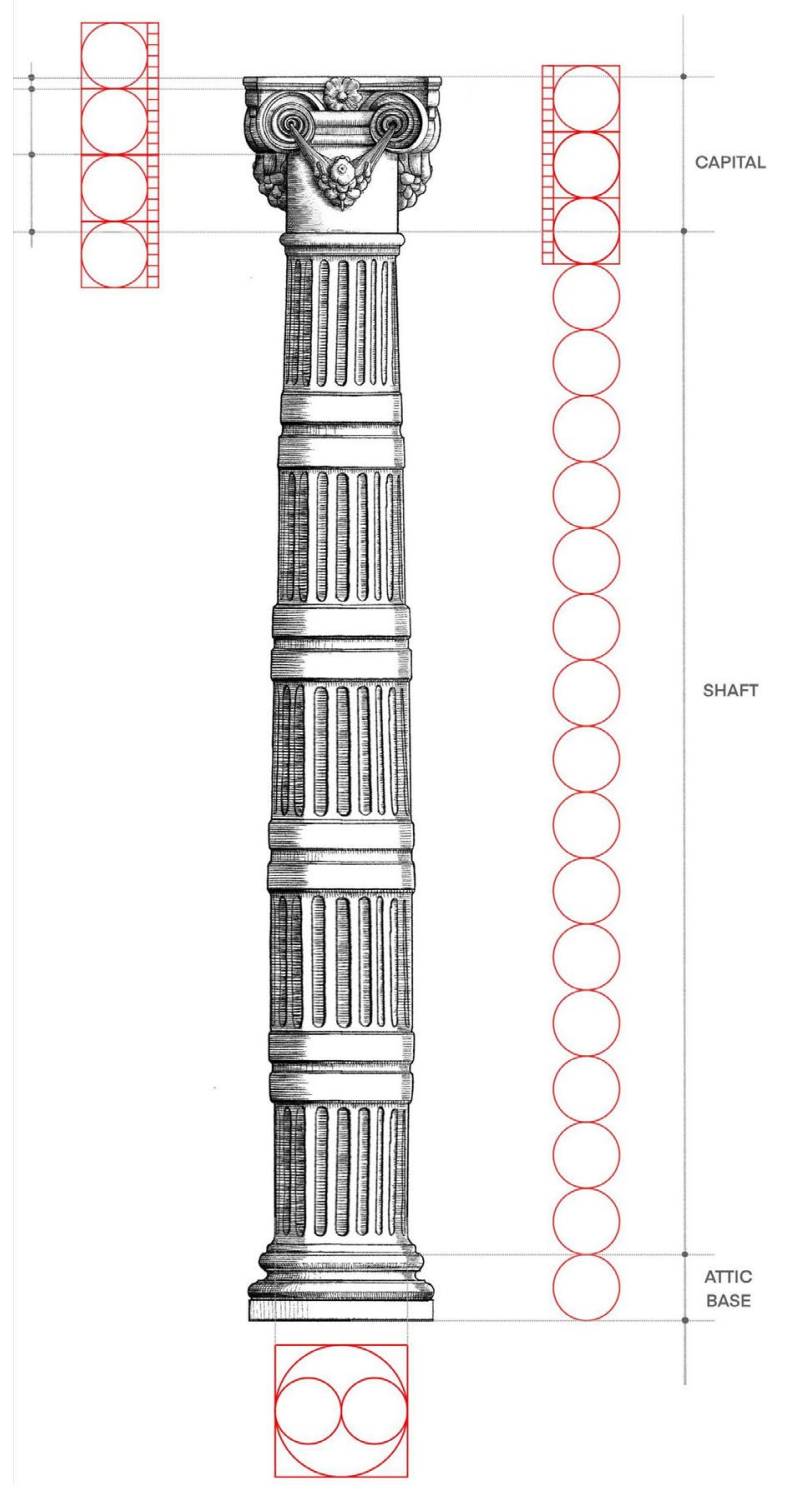

Figure 4. Dimensional analysis of the column. 


\section{SURVEY PROCESS}

\subsection{Visual Survey}

Architectural spatiality is always an extremely complex system because it arises from the interplay of multiple components that are not always easy to distinguish within a "layered" building, if not by those who have great expertise in the field. Without a doubt, this process requires the use of a severe methodology in order to "decrypt" this complexity as it is easy to get lost and not be able to reach the fulcrum of the architectural language expressed by the building itself.

It is never enough to be able to see architecture only with our five sense organs, but it is necessary to know how to "read" it or rather decode it and to do this, it is important to define a rigorous reading methodology that allows us to analyze its articulated language. Before becoming a concrete work, architecture takes shape through drawing, in fact, all designers after having mentally conceived their idea, their project must visualize it through drawing, project sketches, in order to be able to define the formal aspect through a series of successive drawings approaching the final form. Architecture is born with drawing and with drawing it can be analyzed and understood through the detailed analysis of its constituent elements (Docci \& Chiavoni, 2017)

In fact, during the design phase, even if not rigorously, they very often verify the proportions, shapes and architectural components through hand drawing: the production of schematic sketches, geometric patterns, small graphic notes and of analysis of details shows how the practice of drawing becomes a real tool for thinking, understanding methodology and properly critical activity through which a key part of the architectural design process is defined.

The same practice of drawing, understood as a thinking approach, can be applied to the built heritage in an inverse way: that is, while the designer, starting from a formal-functional conception, arrives at the material creation of the work, whoever does the survey wants to reach the essence of the artifact starting from physical reality thus revealing the deep meanings and understanding the processes and languages that are hidden behind the architectural works. Drawing by hand, for the purpose of this specific research, is an essential tool even if it is firmly argued that the graphic analysis carried out by means of visible relief must however be accompanied by a methodology based on precise analytical-mathematical criteria. This possibility, that is, of passing from individual experience to a real scientific methodology, was provided to us by linguists and, in particular, by the structuralist current. Structuralism, as is well known, is not a science, but an operational methodology, which takes its name from the concept of structure, or form, with which a certain phenomenon presents itself to our eyes. The analysis carried out by the structuralist consists in examining a certain event, breaking it down into its constituent parts, to classify them and then recomposing it so as to understand the relationships that mutually bind the individual parts and each of these with the whole. Although at first sight this methodology is a reduction and an impoverishment of reality, it allows, through the modelling of the phenomenon, to carry out a series of observations from different points of view, such as to advance the level of knowledge until reaching a complete vision of the phenomenon examined (Docci \& Chiavoni, 2017).

In this sense, the visual survey with its modalities of graphic explanation, being the result of a schematization carried out by the designer's mind, has a value of understanding and communication of the unique architectural object, since it has already reached the irreducible soul of the building, to a synthetic clarity that computer tools cannot yet achieve.

For example, through the sketches shown in figure 5 we can clearly recognize a mental process, an act of simplification that recognizes the forms, a drawing which mediates the proportions and analyzes the monument, or the atrium of the former Jesuit convent, simultaneously from several points of view, in our case through a plan, a longitudinal section and a cross section that collaborating with each other providing us with a schematic but global idea of the space described.
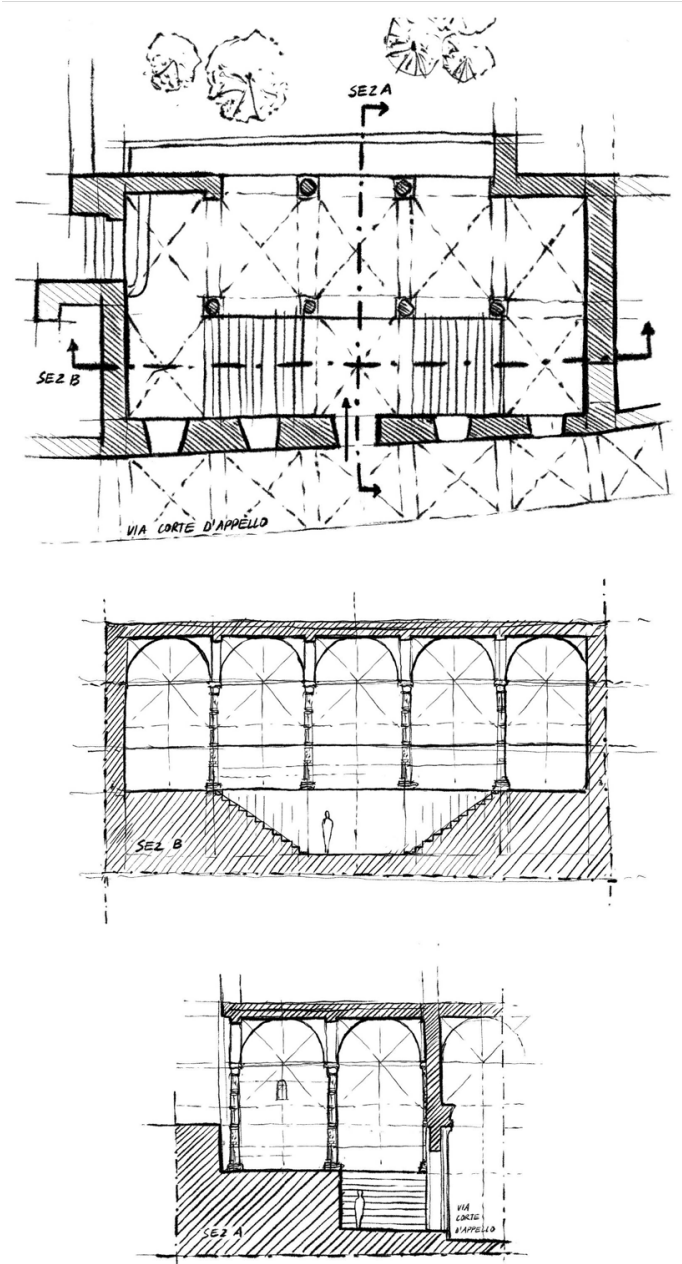

Figure 5. Visual surveys of the atrium.

\subsection{Instrumental Survey}

The survey of the atrium was conducted by laser scanning, using Leica's HDS 7000 phase difference scanner. From the observations resulting from the visual survey and the dimensional data of an initial exploratory survey, it was possible to determine the settings for the scans. In particular, the scanner used allows the setting of a resolution level, identified as the distance between the points detected at a reference distance of $10 \mathrm{~m}$, and a quality level, identified as the precision of the measurements on the single point.

Given the size of the environment to be surveyed, the detail of the elements present and the characteristics of the surfaces, it was decided to carry out the scans at a high resolution level $(6 \mathrm{~mm} / 10 \mathrm{~m})$ and a middle quality level $(12.5 \mathrm{rps}$ at $63.5 \mathrm{kHz})$.

A total of nine scanning stations were carried out, eight of which were internal and one external (Fig. 6), the latter being necessary to survey the thickness of the external wall; the nine 
clouds thus obtained were composed of a total of 269.24 million points.

For maximum compatibility with the BIM software used, Autodesk Revit, the registration and cleaning operations of the point clouds were carried out using the Autodesk ReCap software, whose native format can be imported directly into Revit for the modelling operations. The same software was subsequently used for the segmentation and extraction operations of the profiles for the execution of the typological, geometrical and proportional studies illustrated below.

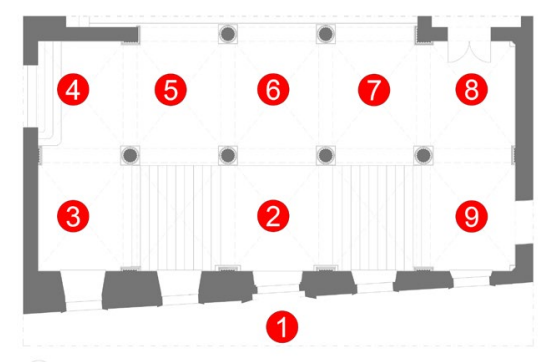

Figure 6. Locations of the scanning stations.

\section{SEGMENTATION OF THE POINT CLOUD}

The segmentation of the point cloud was implemented on the basis of a prior classification and selection of the elements of interest, useful both for the reading of the element and for its subsequent modelling.

It was therefore decided to classify the elements into: columns, pilasters, railings, vaults and architectural.

Each column element has been isolated from the main cloud and cleaned from possible points deriving from noise occurred during the survey. Two vertical sections were then extracted, one oriented along the base axis and one oriented along the base diagonal, the latter passing through the volute of the capital.

In order to have a better reading and interpretation, useful to facilitate the subsequent modelling phases, it was decided to segment each column element in its plinth, base, shaft and capital components.

The shaft has been further segmented into the sub-elements band, drum and collar.

The band element was further segmented into its 3 components: two main bands and one secondary band.

This operation allowed the extraction of 3 horizontal sections of each identified sub-element. Through the sections of base, average height and top of each of the elements, for a total of 27 horizontal sections, it was possible to identify the existence and the course of the entasis of the shaft of the columns. This operation has been found propaedeutic to the development of the algorithm through which the shafts of the columns have been subsequently modelled, as well as particularly useful to the verification of the same.

The same procedure has been applied for the parasta elements. From each railing element 2 profiles were extracted, one horizontal and one vertical. It was not necessary to identify further sections of the components constituting the railing elements.

Each vault element was decomposed into perimeter arches and panels. Of each perimeter arch, 3 longitudinal sections were extracted, intrados - center - extrados, and one transversal section. The course of the vaults was instead verified through the extraction of 4 profiles, 2 passing through the axes and 2 passing through the diagonals.
The architectural was instead divided into the elements of wall, staircase, fixtures and floors. It was not considered necessary in this case to carry out sections prior to modelling, deciding to make a direct import of the cloud of points within the modelling software.

\section{MODELLING}

The modelling was entirely developed through Autodesk Revit software, based on the point cloud processed through Autodesk Recap Pro software. According to the type of elements identified in the segmentation phase, different modelling methodologies were used, as described in the following chapters.

\subsection{Local and parametric modelling}

As far as the architectural elements, pilasters, railings, bases and capitals of the columns are concerned, it has been chosen to proceed with a "classic" modelling, based on the use of extrusions, extrusions on path, unions of extrusions on path generated by different start and finish profiles, creation of solids through the revolution of a two-dimensional profile around a central axis and through the use of geometric Boolean operations.

For each of the elements involved, depending on the level of need, it was decided whether to create a "local" type model, to use a system parametric family, or to create a true external parametric family.

Through the real survey and through the reading and interpretation of the point cloud, it was possible to notice how some walls started from a particularly irregular basic section and then developed in height in an equally irregular way.

Revit does not offer a good management of particularly irregular walls through the use of the system family "wall". To overcome this limitation, it was decided to create a series of local models based on the "wall" type. The walls have been generated by extrusion, joining the solid geometries and subtracting the empty geometries.

For the modelling of stairs and floors it was sufficient to use the dedicated system families, while for the modelling of frames external parametric families were used.

For the modelling of railings it was decided to use the dedicated system family.

The railings included between the columns of the atrium have been divided in the modelling phase into uprights at the beginning and end of the path, obtained by vertical extrusion, interspersed with a perforated intermediate panel, obtained by horizontal extrusion. The generated family therefore keeps the module parameter constant and ignores the division into upper and lower current. All the railings in the case study have the same module.

Not needing to use the family to describe railings with different modules has allowed to avoid parameterizing every single current and internal balustrade, making the modelling phase more agile.

The railings that separate the atrium from the external courtyard have instead been modelled using a system family with constant pitch balustrades included between 2 beams, to which are added side closure profiles of rounded shape.

The bases and capitals were modelled from the horizontal and vertical profiles extracted from the point cloud during the segmentation phase.

The two elements of the pilasters are therefore composed of solid geometries obtained by extrusion of the vertical profiles along a horizontal path, while the two elements of the columns 
are generated by revolution of the vertical profiles around the central vertical axis of the column shaft.

We then chose to parameterize the height of the extrusion profiles of the individual column elements, constraining their proportion in relation to the total height parameter.

A different approach was used for the drums. The drums were in fact all generated through the development of a special modelling algorithm that will be discussed in subsequent chapters, along with the vaults.

The used method renders possible to reuse the same model, readapted of time in time for eventual ulterior studies and comparisons relative to other works of the same age attributable or not to de Vincenti.

The model obtained describes the bases in a manner completely corresponding to reality. The capitals are instead described by synthetic solids, deriving from the critical reading of the constituent elements of the capital, that is collar, volutes and drapes of flowers and fruit.

It has been chosen this type of attitude because the purpose of the modelling in this case, has the objective to describe and to make understand in the best way the composition of the architectural elements.

It is in every case possible to realize a more realistic and detailed model of the capitals through a methodology based on the use of mesh, which will be treated in the following chapters.

\subsection{Algorithmic modelling}

As is well known, modelling complex historical elements in scan-to-BIM processes involves a number of problems often related to the lack of flexibility of the native parametric modelling tools of BIM environments.

An alternative methodology, which has already provided good results in the past, is to parameterise the feature generation process using algorithmic modelling tools. This type of approach overcomes many of the limitations imposed by traditional tools, such as the limited management of nested parameters or the generation of shapes according to complex geometric or mathematical rules. In previous research, this methodology has been applied to elements that are complex from the point of view of form, but presumably based on very precise geometric rules, such as cross vaults or column shafts (Bagnolo \& Argiolas, 2021; Bagnolo et al., 2019).

The identification and application of these geometric rules, derived for example from historical treatises, thus form the basis of the development process of the modelling algorithms, as well as one of their strengths, since the algorithms themselves, by preserving the construction rules used, become a source of knowledge in future uses.

The use of the algorithms already developed allowed a considerable saving of time in the modelling phase of elements that would otherwise have required ad hoc modelling for each object present.

The in-depth research on the atrium and its elements provided the opportunity to further develop the algorithm for the modelling of the shafts; in particular, the aspect related to the entasis, present in the columns of the atrium, and foreseen in the algorithm only for the columns without bands, was improved.

The modelling of the entasis is based on the tracing of the external profile of the shaft according to specific geometric constructions; in our case, considering the observations already stated in the previous chapters on reference treaties, it was decided to transpose the construction proposed by Vignola (1763) into an algorithm.

The tracing of this profile makes it possible to identify at each point of the shaft a reduction or enlargement ratio to be applied to the profile of the shaft itself, thus obtaining the required deformation.

In the case of shafts without bands, the modelling of the entasis can take place by means of a simple loft operation applied to a sufficiently numerous series of profiles of constant shape but appropriately scaled according to the dimensional ratios cited.

With regard to banded shafts, on the other hand, this logic is not immediately applicable since it is not possible to indiscriminately section the shaft to obtain the profiles to be scaled.

The solution adopted therefore envisages the modelling of the shaft, subdivided into drums and bands, without taking into account the entasis, in order to obtain a series of section planes placed at the beginning, in the middle and at the end of each element; to do this a routine has been prepared which, once the undeformed shaft has been assembled, obtains for each element, whether it is a drum or a single component of the band, three elevations corresponding to the base, the middle and the top of the element.

For each element, the three indicated sections are then extracted, which are then scaled according to the relative ratio between straight shaft and deformed shaft; a loft is then applied to these scaled sections to regenerate the deformed element.

In anticipation of possible future applications of the routine described above to case studies in which particularly complex geometries may be involved, and in which the application of a curvilinear loft may be excessively onerous in terms of resources, it was decided to implement a further option to simplify the process; this option provides that for each element only the extreme sections are obtained and scaled, thus generating truncated cone extrusions by loft.

In this case the result is an approximation similar to that given by a polyline for the representation of a curve.

In this specific case, as mentioned, this approximation was not necessary given the relative simplicity of the calculation required (Fig. 7).

Finally, again with a view to having an algorithm with the widest possible application, it was decided to develop a further part of the routine which, instead of the entasis profile, would instead generate a profile with only tapering in the upper two thirds of the shaft.

This type of deformation is in fact often cited as an alternative to entasis in the cases of the Doric and Tuscan orders (Vignola, $1763)$.

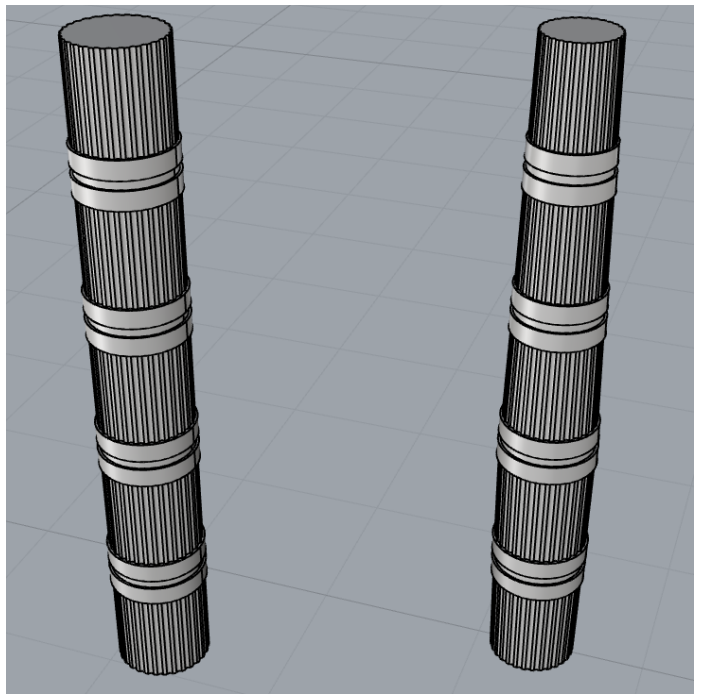

Figure 7. Algorithmic models of the shaft, on the left without entasis deformation and on the right with the entasis. 


\subsection{Highly detailed elements: the case of capitals}

Elements such as capitals require a different reasoning from the one we have seen so far. Indeed, in our case, they present particularly complex and detailed geometries that do not lend themselves to effective modelling with standard tools. Aubin (2014) has well illustrated how it is possible to model this type of elements through parametric modelling tools in Revit, but at the same time his work also shows how such an approach can be unfruitful when it is necessary to reapply it several times to similar but not identical elements. Two possible ways, conceptually opposite, are the use of mesh models or highly synthetic parametric models. In the case of mesh models, these can be obtained directly from appropriately cleaned point clouds, providing a very detailed but unmodifiable models; they are therefore not reusable for other case studies unless discrepancies are accepted.

The use of synthesis models, on the other hand, would offer the possibility of modifying the single model by adapting it to the various application cases, at the price of losing the details in favour of a more conceptual model, comparable in logic to those described by a LOD 200 (BIMForum, 2021).

In our case, since we want to privilege the recognition of the typology and function of the element rather than the single details, and preserve the coherence of the modelling method, we decided to opt for the creation of simple synthetic models created using the classic modelling tools offered by Revit.

Through the modelling methods described, it was then possible to generate the entire atrium virtual environment; the final result is shown in the figure 8 .

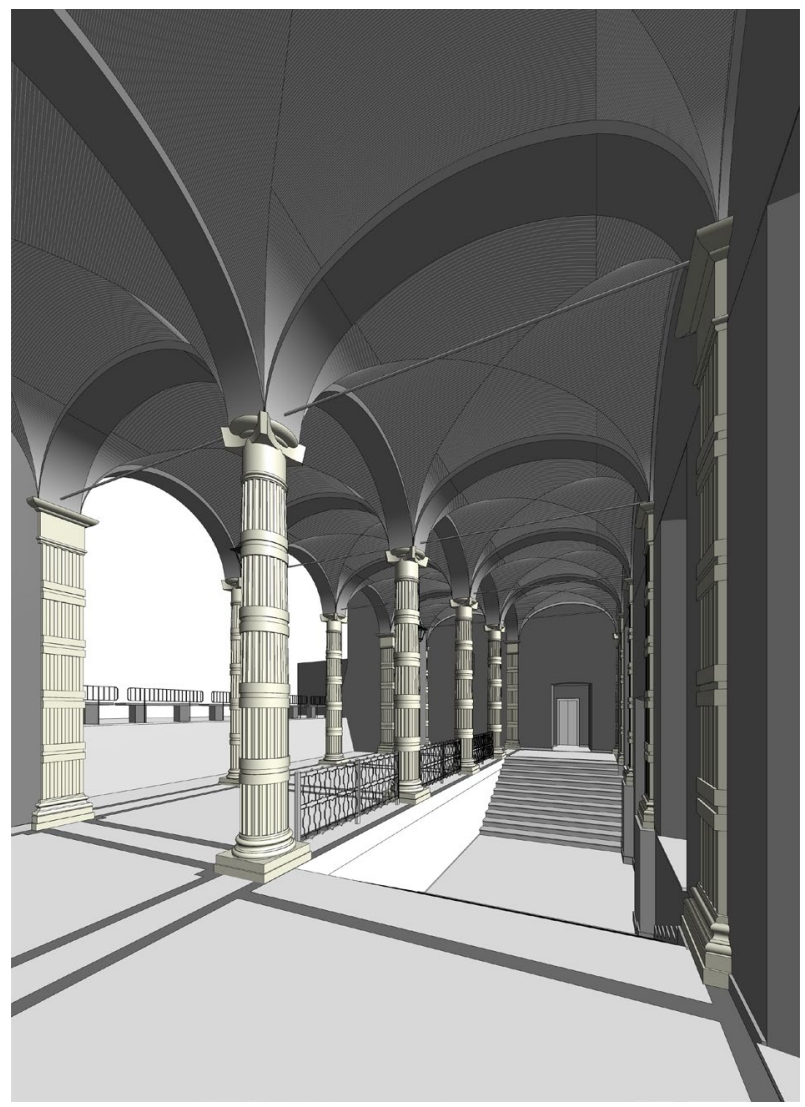

Figure 8. Internal view of the final model.

\section{FURTHER DEVELOPMENTS AND CONCLUSIONS}

\subsection{Possible uses of the models}

The 3D models produced, in accordance with the BIM philosophy, are designed to be usable in a wide range of applications and disciplines.

Geometric modelling that dimensionally accurately represents the case study, coupled with the potential for enriching the elements with physical information from the BIM environment, allows, for example, static analyses of structures to be carried out. In particular, past experiments have shown how the surfaces of the intrados of the vaults, procedurally generated through the algorithms used in this paper, can offer a sufficiently limited level of error for the execution of analysis on the stresses or deformations of the vaults (Argiolas et al., 2019); in the same way the columns, modelled algorithmically, are integrated into the BIM model in the same way as a classic column family, allowing the same static treatment.

With regard to the uses for communication, there are countless examples in which BIM models have proved to be extremely functional in the creation of virtual environments for educational or informative purposes (Osello et al., 2018). In particular, in the case of heritage, models such as the one obtained can easily become the basis on which to develop augmented reality applications, virtual tours or even serious games; these applications have on several occasions proved capable of promoting the communication of heritage thanks to the implementation of interactions between the user and the virtual environment.

Finally, it should be remembered that the very nature of BIM models, or in the specific case HBIM, to act as a container / database of information of a multidisciplinary nature, makes them of extreme interest for the documentation and management of heritage, becoming an important support for studies on the state of conservation of architecture and the organisation of restoration operations for its preservation.

\subsection{Conclusions}

The research demonstrates how the drawing on location together with the design of the architectural orders and the visual survey constitute fundamental steps for a correct reading of historical architecture. The same operations carried out on the real object are repeated on its digital cast of the point cloud, in a constant verification of these different knowledge approaches that proceed in parallel.

The next phases of the research foresee the detailed analysis of the results of the survey in order to be able to trace the architecture of the atrium to a specific architectural order. Starting from the capital, the Renaissance treatises and especially that of the Baroque era now open to two hypotheses. The first brings our case study back to the category of Ionic four-sided capitals, the second to a variant of composite capitals. Now the second hypothesis seems to be the most accredited but further analyses are needed before reaching a conclusion.

In parallel, some experimentation on the use of virtual models for communication will be carried out.

\section{ACKNOWLEDGEMENTS}

Research project funded by Fondazione di Sardegna - year 2019. Surveying, modelling, monitoring and rehabilitation of masonry vaults and domes (RMMR). CUP: F72F20000320007 


\section{AUTHORSHIP CONTRIBUTIONS}

Raffaele Argiolas carried out the laser scanner survey and developed the modelling algorithms.

Raffaele Argiolas and Simone Cera elaborated the point clouds and made the BIM models.

Raffaele Argiolas, Simone Cera and Giancarlo Sanna. elaborated the figures.

Although the study was jointly performed by the authors, most of the paragraphs 1 and 2 were written by Vincenzo Bagnolo; most of the paragraphs 3.2, 5.2, 5.3 and 6.1 were written by Raffaele Argiolas; most of the paragraphs 4 and 5.1 were written by Simone Cera; most of the paragraph 3.1 was written by Giancarlo Sanna; the Conclusions were jointly written by all authors.

\section{REFERENCES}

Alberti, L. B. (1485). De Re Aedificatoria.

Argiolas, R., Cazzani, A., Reccia, E., \& Bagnolo, V. (2019). From LIDAR data towards HBIM for structural evaluation. ISPRS - International Archives of the Photogrammetry, Remote Sensing and Spatial Information Sciences, XLII-2/W15, 125-132. https://doi.org/10.5194/isprs-archives-xlii-2-w15-1252019

Aubin, P. F. (2014). Renaissance Revit: creating classical architecture with modern solfware. G3B Press.

Badenko, V., Fedotov, A., Zotov, D., Lytkin, S., Volgin, D., Garg, R. D., \& Liu, M. (2019). Scan-to-Bim methodology adapted for different application. ISPRS - Int. Arch. Photogramm. Remote Sens. Spat. Inf. Sci., XLII-5/W2, 1-7. https://doi.org/10.5194/isprsarchives-xlii-5-w2-1-2019

Bagnolo, V., \& Argiolas, R. (2021). Scan-to-BIM Process Versus 3D Procedural Modelling of Gothic Masonry Vaults. In From Building Information Modelling to Mixed Reality (pp. 17-31). Springer.

Bagnolo, V., Argiolas, R., \& Alessandro, C. (2019). HBIM for archaeological sites: from SFM based survey to algorithmic modeling.

BIMForum. (2021). LOD Specification. https://bimforum.org/LOD/

De Fusco, R. (1968). Il Codice dell'architettura. In Antologia di trattatisti. Edizioni Scientifiche Italiane.

Docci, M., \& Chiavoni, E. (2017). Saper leggere l'architettura. Gius. Laterza \& Figli Spa.

Garofalo, E. (2012). Le architetture della Compagnia di Gesù in Sardegna (XVI-XVIII secolo). La arquitectura jesuítica, 141-192.

Gregotti, V. (1985). La geometria in funzione dell'architettura a grande scala. In P. Grandinetti (Ed.), "La geometria in funzione", Quaderni del Dipartimento di Architettura e Progettazione Urbana $n^{\circ} 10$, IUAV.
Kaufman, E. (1968). Architecture in the Age of Reason: Baroque and Post-Baroque in England, Italy and France. Dover.

Le Duc, V. (1875). Dictionnaire raisonné de l'architecture française du XI au XVI siècle. Paris.

Maltese, C., Serra, R., Madonna, M., Trigilia, L., Segni Pulvirenti, F., Sari, A., Saiu Deidda, A., \& Schirru, M. (2012). Avanguardie architettoniche e urbane nella Sardegna della prima epoca moderna. Ricerche di Architettura: Nuove Prospettive per l'architettura nella Sardegna del XXI secolo, 150.

Morgan, M. H. (1960). Vitruvius. In The ten books on architecture. Dover Publications New York.

Murphy, M., McGovern, E., \& Pavia, S. (2009). Historic building information modelling (HBIM). Structural Survey, 27(4), 311-327. https://doi.org/10.1108/02630800910985108

Osello, A., Lucibello, G., \& Morgagni, F. (2018). HBIM and Virtual Tools: A New Chance to Preserve Architectural Heritage. Buildings, 8(1). https://doi.org/10.3390/buildings8010012

Pocobelli, D. P., Boehm, J., Bryan, P., Still, J., \& Grau-Bové, J. (2018). BIM for heritage science: a review. Heritage Science, 6(1), 1-15.

Scano, D. (1934). Forma Karalis. Cagliari: Edizioni La Zattera, 210.

Vignola, G. B. d. (1763). Regola delli cinque ordini d'architettura. 